\title{
DEBATE / DEBATE
}

\section{Epidemiology of the $21^{\text {st }}$ century and cyberspace: rethinking power and the social determination of health*}

\author{
Epidemiología del siglo XXI y ciberespacio: repensar la \\ teoría del poder y la determinación social de la salud
}

\section{Jaime Breilh'}

\begin{abstract}
The study of epidemiologic processes as a form of socially determined movement requires a renewed understanding of the social order, and thus, an updated understanding of the social relations that move society. Recently, the dominance of big corporations on cyberspace has become visible as a new historical process that conditions the social order and extends the technological subordination of daily life, therefore expanding community massive submission to standard conducts. The new digital technological revolution, about which some frightening prognoses are made for the next decades, could easily imply the advent of an era of radical subsumption of life processes. This will negatively affect not only our general way of living, thinking and planning, but also our deepest daily intimacy. This movement implies radical effects on health which we call cybernetic determination and subsumption. This novel process raises new questions on public health and prevention; but also requires a new reading of reality, a rethinking of human life and health, of its social determination, which implies the need for new new categories and analysis and renewed challenges for critical epidemiology.
\end{abstract}

Keywords: Epidemiology. Health cybernetic determination. Power theory.

*Conference to the IX Brazilian Congress of Epidemiology, Centro de Convenções da Vitória, Universidade Federal do Espírito Santo, Brazil; September $9^{\text {th }}$ 2014; proposal for publication.

Universidad Andina Simón Bolívar - Ecuador.

Corresponding author: Jaime Breilh. Quito (Pichincha), Ecuador. Área de Salud, Universidad Andina Simón Bolívar. Edificio Olmedo, 6to piso; Ave. Toledo N2280, Quito, Ecuador. E-mail: breilhjaime@gmail.com

Conflict of interest: nothing to declare - Financial support: none.

972

REV BRAS EPIDEMIOL OUT-DEZ 2015; 18(4): 972-982 
RESUMEN: El estudio de los procesos epidemiológicos como un movimiento socialmente determinado requiere de una nueva comprensión del proceso social y de una comprensión renovada de las relaciones de poder que mueven a la sociedad. En los últimos tiempos, la consolidación del dominio de las grandes corporaciones sobre el ciberespacio se ha hecho visible como un proceso histórico novedoso que marca el orden social y expande las posibilidades tecnológicas de subordinación de los modos de vivir, amplificando el sometimiento de las colectividades a patrones de conducta masiva. Los malos usos de la nueva revolución tecnológica digital sobre los cuales se hacen aun nuevos y atemorizantes pronósticos para las próximas décadas, implican el advenimiento de una era de subsunción radical de los procesos de la vida, que afectará negativamente no solo nuestro general modo de vivir, pensar y aspirar, sino nuestra más profunda intimidad cotidiana. Se trata de un movimiento con efectos radicales en la salud que podemos denominarlo como determinación y subsunción cibernética. El carácter novedoso de este proceso plantea nuevas preguntas al campo de la salud pública y la prevención; requiere de una relectura de la realidad y de un giro necesario para comprender nuevas dimensiones de la determinación social de la vida y la salud, lo cual presupone la aplicación de nuevas categorías del análisis y desafíos inéditos para la epidemiología crítica.

Palabras clave: Epidemiología. Determinación cibernética de la salud. Teoría del poder.

The study of epidemiologic processes as socially determined movement requires a new understanding of the social order, and thus an updated understanding of the power relations that segregate society in classes, crossed by ethnic and gender relations. The appraisement of social determination, therefore, implies the understanding of social relations that divide the population into classes, pervaded by ethno-cultural and gender conditions.

Such segregation of social life styles is fundamental in the method of critical epidemiology, because healthy or unhealthy modes of living that characterize different social classes, which at the same time expose their members to unhealthy conditions, or conversely healthy collective patterns that promote their health, finally determine typical collective patterns of exposure and vulnerability, their general quality of health, and the specific pathological processes that affect them.

Critical epidemiology ${ }^{\star}$ implies a profound rupture with conventional understanding of health, by overcoming the lineal and reduccionist logic of positivist epidemiology.

${ }^{\star}$ Critical epidemiology is the interdisciplinary and intercultural study of the processes which determine the production and distribution of collective health, which encompass a set of social relations, ideas, and organized forms of practice that make up the social reproduction of human societies, as groups formed around strategic interests imposed by the political economic system, groups that are characterized by typical modes of living of its members, according to their class insertion, cultural and gender filiation and also condition the individual life strategies that are made possible. This set of processes must be analyzed through its interrelations in order to explain the socio-environmental roots of collective health, as well as the bio-psychological expressions that appear in the phenotypic and genotypic conditions of individuals. Conditions understood as making part of the historical movement of our societies, subject to the logic of capital accumulation and the strategic interests of powerful hegemonic groups. This interpretative cycle demands critical emancipatory thinking, as well as a conscious and organized public-social strategy, paralleled by the methodological recognition of complexity as an essential feature of health. An interpretation that provides lever knowledge and an ethical reference for the struggle to overcome the unhealthy modes of living and destructive forms of metabolism between society and nature, which the system reproduces in the general (macro), particular (meso) and individual (micro) domains of social life; a struggle that seeks to replace them with sustainable, sovereign, equitable and biosecure patterns. This type of agency is central to the development of a renewed profound understanding of prevention and health promotion, and for the consolidation of protective support processes-collective, familial and individual- that finally are reflected as physiologic -phenotypic and genotypic- and psychological forms, which sustain good quality biological and psychological living, and make possible longevity, immunity, plentiful physical potential at all ages, and the enjoyment of pleasure and spirituality.

973

REV BRAS EPIDEMIOL OUT-DEZ 2015; 18(4): 972-982 
It replaces lineal reductionist thinking, that places the individual at the center and considers its individual attributes (variables) as the essential elements, analyzing reality as a fragmented set of external risk factors that surround and can be associated to the individual. Those empirical atoms of reality are then classified as "social causes", "environmental causes" or even as "causes of the causes". Based on this view, conventional epidemiology stratifies the population according to their individual attributes and correlates them with those risks or causes. On the contrary, critical epidemiology applies the notions of complexity, interdependence and movement to understand health as a multidimensional process that includes the socio-historical dynamism and interrelation between collective and individual processes. It intertwines the broader (macro) or general processes of society - which establish the logic of social development, its defining economic, political and cultural conditions and the corresponding forms of metabolism with nature; the typical modes of living of social class patterns with their gender and ethno cultural relations at the particular (meso) domain; and the individual styles of living and sociobiological (phenotypic and genotypic) individual processes.

Thus, it overcomes the notion that collective health is reduced to the statistical aggregation of individual data about individual characteristics and risks. It challenges the positivist notion that epidemiological methodology merely demonstrates quasi-experimental associations between risk variables and health outcomes. And also, it defies the empirical notion that the connection between individual and social phenomena is only external. Therefore, while empirical epidemiology reduces its method to a simple search of "casual" associations (constant conjunctions) between empirical "risk factors" and personal diseases. Critical epidemiology develops explanations on how collective health conditions are determined. It seeks to relate the general logic movement of society with the occurrence of healthy or unhealthy modes of living of different social classes, in certain space/time scenarios, and relates that movement with individual styles of living and the bio psychological conditions of individuals.

Critical epidemiology questions the lineal reductionist logic of empirical epidemiology and also the pharmo-bio-medical reasoning that prevails in conventional functionalist public health. In order to do so, it has to demostrate the tight relationship that exists between the health outcomes in different social groups and the processes generated by the social reproduction of capital accumulation. The understanding of this movement is crucial for explaining how the economical and sociopolitical system affects human health and nature, how it operates to dismantle the peoples sovereignty, disassembles solidary social relations generating a frenetic consumerism and multiplying unhealthy consumerism that affect sustainable development. This is why a healthy society should be organized to comply at all moments and in all social settings for basic conditions of a healthy life: sustainability, sovereignty, solidarity, and full biosafety. Limits and long term effectiveness of personal medical care are established by this complex social determination.

If we assume critical, innovative thinking as a landmark of integral scientific objectiveness and if we are conscious of the complexity of social life and the ethical implications of 
health actions, we can decipher the real requisites of hard rigorous epidemiology, which do not only depend on the accuracy, confiability and validity of its empirical methods, calculations and observations but on a rigurous understanding of how a redefined ethical-political role for epidemiological research, demands new criteria of objectiveness and research subject understanding, when defining and explaining the health situation integrally, without, the ambiguity and empirical reductions that underlie mathematical sophistication.

In the beginning of this century, global exponential growth of accelerated capital accumulation mechanisms and the corresponding concentration of wealth, imply the multiplication of unhealthy living modes, which prevail in most subordinated social froups, but especially upon the working and middle classes. Moreover, what we analyze in this pages is the fact that the reproduction of social exploitation, inequity and subsumption, find new modes and instruments in virtual space technology.

\section{IS THERE A CYBERNETIC PHASE IN THE SOCIAL DETERMINATION OF LIFE AND HEALTH?}

No matter from what theoretical-epistemological or ideological-political horizon we approach the present crisis of natural and human life, we have to recognize the advent of new forms of virtual or cybernetic unhealthy subordination of human life. These not only include economical exploitation and domination by force, but new subtle forms of hegemony and social subsumption - most effective and less obvious - that are reproduced in the cybernetic domain. Thus, although epidemiology has always studied the role of inequitable social patterns, in the last decade the cybernetic sphere has arisen as a new means for their multiplication in the $21^{\text {st }}$ Century. One of our present taks, therefore, is to understanding of this new phenomena and the transformation of social rule and power relations.

Despite the noteworthy research on social inequity that one can find in the literature of political economy, sociology, the political sciences and critical epistemology, we must motivate the development of awareness about the new complexity of power dynamics, a study object that is transcending conventional critique about the capitalist State, its power relations and its ideological conflicts. .

We need to apply new categories for understanding the present capitalist order, conducting two interdependent operations, which are essential for understanding how to operate in a world where economic accumulation is produced also by cybernetic mechanisms. In the first place, we need to reexamine the "classical" categories used by different schools to study power relations in the social process such as: State, class domination, subsumption, hegemony, instrumental reason, disciplinary power or coloniality. These are persuasive useful concepts, which have allowed for compelling interpretations made by the critical theory of social power and asymmetry: notions developed by different schools of marxism, of the Frankfurt School of Critical Studies, Foucault's disciplinary theory, or modernity/ coloniality criticism. 
However, secondly, we must look beyond through new categories needed to unravel what we are calling cybernetic determination.

Contemporary epidemiological research would commit a serious mistake by neglecting the accumulated facts about the negative impacts of Internet in our lives and health. We are not referring only to the massive and almost permanent use of digital communication, mailing and social networks, but to the accelerated expansion of an omnipresent system of determination, described in a recent report by the Pew Research Center:

A network computational environment, global, involving, invisible, developed around the continuous dissemination of intelligent sensors, cameras, computer programs, databases and massive data centers, in a worldwide informatics structure known as the Internet of Things. The realities of this world full of data raise very serious concerns about privacy and capacity of people to control their own lives [...] It monitors and extracts information from our routine, profiles us and focus on us, with which social, economic and political conflicts will be amplified. ${ }^{1}$

Reflecting on these problems by no means implies a lack of awareness of the importance of technological advances in the digital world, nor denying the usefulness of the global network, yet it is a call to incorporate a critique of the virtual sphere of our collective and personal lifes in the study of social order and power; this is a necessary task, because this movement reproduces and extends the social relations of our world. A necessary shift of our perspective of importance to a renewed understanding of the social determination of our life, that presupposes the adoption of new categories of epidemiological analysis. Thus, we propose to focus on today's new problems of the involving market society, such as: Is there a phase of cybernetic capital accumulation nowadays? Beyond the classical subsumption in the workplace described by Marx, Is there a cybernetic or virtual subsumption beyond what some authors call the subsumption of consumption? ${ }^{2,3}$ In the field of social domination, is there cyber control or cybernetic repression? If these novel conditions of capitalism contribute to mold our society, it would mean that they make part of the social determination of health and, therefore, become an important subject of epidemiological research.

A main challenge of $21^{\text {st }}$ century epidemiology is rethinking the power relations that determine our modes of living and distribute inequitable patterns, by incorporating new concepts that capture the new forms of social explotation, submission, subordination, persuasion and conditioning, which make part of the social order under accelerated capital accumulation.

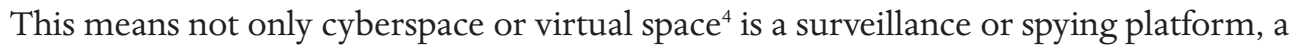
kind of cyber-panoptic - using Foucault's metaphor — , but it is also a highly organized and globally expanded sphere where cybernetic technologies converge for the acceleration of capital accumulation mechanisms, where processes co-determine our ways of living, thinking and aspiring — which I propose to designate as cybernetic determination and subsumption. 
Thus, our social system is not merely a police State. ${ }^{5}$ By saying this by no means are we implying that its omnipresent system of citizens espionage is not an important characteristics, we are only stressing the fact that it is misleading to define the power relations of 21 st century capitalism by this sole expression. We do live in a sophisticated police State, but mainly we live under the rules of fierce capital accumulation, an economic process that tends to an omnipresent control; a period of accumulation based on three acceleration mechanisms: the convergence of technologies that speed up and make cheaper the extraction of plusvalue; the fraudulent dispossesion of vital resources; and the opportunist exploitation of social shock. These make up the material basis that generates the need for a policial control network,, created to reinforce surveillance, to better focus on repression, and to domesticate the routine of the worker population. Lets review the main facets of cybernetic determination.

The convergence of digital technology and hypermedia has enabled new forms of accumulation and made possible in recents years the existence of cognitive capitalism, associated with the production of goods through knowledge. Its proponents argue that,

digital technologies open a completely new perspective for production. They have used the most common, most public ("informal") qualities of work force, i.e. the language, communicativerelational action. This is the result both of the Toyotist revolution, as well as the generalized application of information technologies ("linguistic machines") and of outsorcing [...] Without the new digital and communicative technologies, it would have been impossible to make use of language as a direct productive input dissociated from the physical space. Thus, creation of a virtual space means to language what the geophysical space means to the production of material goods $[\ldots]$ value creation has increasingly been characterized by immaterial and symbolic elements. In some aspects, this situation is not different of the creation of capital gains in financial markets. ${ }^{6}$

According to Piero Sraffa - another exponent of knowledge capitalism - the capital accumulation equation of Fordism, changed in this new period. It no more corresponds to the D-M-D' equation, but the D-M(K)-D' form, which incorporates the production of cash value through knowledge $(\mathrm{K}){ }^{6}$

In such case, the novel nature of this processe would not consist in the appearance of a knowledge-based economy, but it would consist on the formation of a "subgroup of economy" that is guided by the deliberated production of knowledge as a productive factor" ${ }^{6}$ This process, I would add, when applied in universities and in the social sphere implies a deadly blow on critical emancipatory knowledge; it encourages what has been called "post academic science"?

As discussed, the cybernetic virtual space becomes a new platform or material basis for accumulation and instantaneous circulation of goods; for marketing of ideas and protocols; for accelerated flows of information that is essential to an accelerated accumulation; the reproduction ways for the subsumption of work and consumption; and of the reproduction 
of political and cultural goods, which oxygenate the new modality of accumulation. Hence, some contemporary theoreticians of communication argue, that the cybernetic space operates as a social disciplining and conduct robotization sphere. ${ }^{8}$

The virtual environment also works for the promotion of sales and fabrication of commercial frauds. For instance, semi-clandestine shops have been reported in Bangladesh, where employees work under miserable conditions, for minimal wages - as low as $\$ 120$ per year - in three-shift systems. They produce under payed request thousands of clicks or hits for Internet page counters which falsely enhance the rates of acceptance of a variety of products and thus manufacture a fraudulent appearance of on-line popularity. By paying the workers of these so called "clic farms" \$ 15USD for each 1,000 pulses in "I like" or "Very good" the commodities can show high consumer demand. ${ }^{9}$

In addition, virtual fraud fabrication is also applied to political propaganda or dissuasion in social networks. Mexico has been a privileged scenario of the fraudulent use of techniques that aim at controlling trending topics (current themes), positioning those benefiting the powerful and eliminating the critical or social protest trending, by flooding the network with messages of the sort one can create the appearance of a spam trend, and therefore eliminate the trending from the network. As explained by an expert from a specialized center that recruits adolescents of a certain political tendency: "another hashtag with bots is created so that protest themes are displeasured or disappear of Twitter ranking", ${ }^{10} \mathrm{With}$ this kind of cybernetic resources multiplying in Facebook or Twitter pages, one can reproduce a false popularity of some people or ideas or attack critical leaders and ideas.

The unconscious proletarianization of Internet users is another worrying facet of the problem. Social networks are considered spaces for legitimate acceleration of accumulatio. The multimillionaire exponential growth of companies as Facebook is produced on the base of commercial use of "unconscious" work from many users/workers of whose information the firm can extract gains. The scaling awareness about this circumstance has triggered movements like "salaries for Facebook", which not only symbolically demand payment for their job, but also analyze the transfiguration of elements of friendship or familial love into commodities.

Huge search engines and social networks not only surreptitiously usurp and commercialize millions of private and confidential data from users' accounts by inscribing them in their process of capital accumulation, but also use such information to investigate behavior patterns and expand a consumerist counter-culture that competes in the worldview of youngsters with values and elements of their own cultures.

Another expression of the role of this relatively new technological platform is the dispossession strategies under digital control. In past months, the world media published the emblematic case of Oakland city, located in the beautiful Bay of San Francisco. The location in the area of Google headquarters, in the neighborhood of Silicon Valley - which is widely documented as a key element of the contaminating electronic industry - determined an "invasion" of technocrats to Oakland, provoking not only a generalized raise of prices, but also the expulsion of traditional city residents and communities, degrading their life 
patterns and forcing them to a resistance movement. ${ }^{11}$ With the objective of consolidating this de facto dispossession, millionaire funds were approved for the creation of a Domain Awareness Center (DAC) in the end of July 2013, to surveil and invade the privacy of Oakland citizens. This center is destined to operate a wide spying network with the use of cameras and digital resources from schools, community centers, roads, public and private spaces. ${ }^{12}$

Finally, the third accumulation mechanism that completes the technological convergence and dispossesion strategies is the productive use of social shock and fear. A phenomenon that can be illustrated by the massive sale of antivirus programs and electronic mechanisms for network and cloud safety, with the purpose of controlling alleged cybernetic attacks.

These tendencies reinforce a techno-cyber-bureaucratic culture in this period of capitalism, which gives preeminence to the production and transmission of instrumental knowledge that is productively useful, and overestimating technology as the only and most important way to development. Thus, it is a culture that becomes an essential element of the functionalist model; associated to a technocratic vision, with the management of technology, and a knowledge geared towards productive efficiency. The objective being to reduce prices and to make more efficient the processes of codification, transmission and acquisition of knowledge, as well as enhancing the effectiveness of techno-administrative processes by expanding the new linguistic and communicative technologies (NTIC, Internet, among others) ${ }^{13}$ Hence, the elements and values of peoples, their cultures and rights are not only set aside, but are frequently hounded.

All that being said, we must assume with irreducible responsibility that the struggle for consistently healthy societies and the defense of the real quality of human life in the $21^{\text {st }}$ century, in other words the advance of our health prevention and promotion programs, must incorporate the action needed to confront antagonize the bad applications of cybertechnology and a progressive understanding of the role of cyber phenomena we have outlined in the social determination of health. There are no elements of our daily lifes, not withstanding its intimate facets that are not conditioned or linked to the cyber-sphere.

From the perspective of critical epidemiology we have come to understand that there are four principles of a heathy life — as we have said, the 4 " $S$ " of life (sustainability, sovereignty, solidarity and biosecurity). Besides, the social processes that affect these four conditions operate in five domains (work; consumption and domestic life; social organization/supports; culture and construction of identity; and metabolism of social life with nature). We are now beginning to understand that all such principles and five dimensions are also conditioned by cybernetic processes.

It seems obvious that opposing critically cybernetic subordination by no means implies a proposal for disconnection from the virtual sphere. That would only deprive us of the positive applications and power of cybernetic tools; an alternative that would be disadvantageous in the least or clearly impossible. What we need is to promote is collective awareness and mobilization to defend net neutrality, protect the open, neutral, democratic, solidary, non-commercial character of the original proposal of the global network, in order to protect it, strengthening its best uses, and putting a stop to the trends of corporate monopolies 
that strive for its privatization as well as to those that adhere to cultural submission in the network.

Furthermore, it is clear that accomplishments such as Edward Snowden's declaration about massive spionage, or the frequent cases of cyber bullying that are affecting our children and adolescents, provoking their mental suffering and even suicides, are nothing more than the tip of the iceberg of a much deeper and complex problem, that the Latin American Collective Health and Social Medicine movements must incorporate into their working agendas. They are only the ugly and visible face of the new ways of privacy, security and sovereignty loss, that are destroying our organized social supports, our global class relations and connections, by replacing them with a false sociability characterized by external episodic virtual contacts in contexts of extreme individualism and vulnerability in the face of big business.

In order to complete our analysis and raise our awareness about the pressures of powerful corporations for controlling and stratifying the network to destroy net neutrality we must keep in mind the intense big business lobbying that is operating in the Congress of the United States in order to reaffirm complete control of cyberspace. The Communications Federal Commission of the United States, controlled by democrats, is striving to use a legal reform mechanism to break the equal access lock to the network ("net neutrality") and to allow big service providers to operate under two systems: a fast one for super-clients and a slower cheaper one for citizens and the common. It becomes evident that this strategy aims to institutionalize present hidden cyber inequity as an effort to reinforce social inequity from virtual inequity. A millionaire lobbying of net giants, colluded with the political elites that serve their interests. This move to reinforce an imperialistic logic also in cyberspace is without a doubt one of the biggest threats that we the people face both in broad terms and in the specific case of health rights.

Fortunately, the democratic members of society, social organizations of the world are rejecting the creation of classist and discriminative provision for the Internet. An urgent awareness that has also started to have a repercussion in some governments. In this regard, we find the promising policy of the Brazilian Congress, which approved in March 252014 , a law project that regulates the network, protects its neutrality and prohibits a systematic spying, thereby creating a hopeful precedent. ${ }^{14}$

Social determination processes are also relevant for the individual and biological domains, which constitute the clinical side of things. Thus, in this case for instance, we have to mention impacts like the neurological and psychological impacts of intensive exposure to Internet of young consumers, a key feature of $21^{\text {st }}$ century capitalism and one of its most frequent cultural traits. As explained by neuro-physiologist Susan Greenfield — recognized as one the most important European neuroscientists- in a presentation in a London BBC program, ${ }^{15}$ the addictive exposure of youngsters to Internet and the virtual world, not only restricts them to a bi-dimensional world in which they do not develop many skills of an authentic sociability - that can only be built through real contact with people - touching them and looking at their eyes — ; but additionally, it ends up affecting their brains, 
deteriorating their language skills and their sociability, which require an integral pattern of interpersonal communications, She argues that one can be connected to thousands of Facebook or Twitter users, but they will be mere "audience" and not real communicating friends. Hence, we are deprived of empathy capacity, of face-to-face skills, of deep human communication and become cyber-citizens, trapped in extreme solitude. Nothing better than this type of cyber socialization to reproduce the individualist and consumerist civilization required by the market society.

Not withstanding the fact that Greenfield's arguments were contested by Oxford researchers in an editorial of the British Medical Journal, which bluntly disqualify her important denounce because supposed lack of sound scientific evidence, we insist in bringing them to account not only inspired by the ethics of precaution but because of her well documented response to her detractors. Moreover, there is a well known and documented dossier of emblematic cases of "scientifically based" rejections of studies that potentially endanger big economic interests; an over dimensioning of critique aimed at disqualifying important scientific alerts through technicalities.

These brief reflections constitute a provocation to trigger a debate and to defy the new forms of economic subordination and psycho-cultural Subsumption that affect collective and individual wellness and healthiness. Even though it was impossible to accomplish through these short pages a profound discussion of such a complex problem, and aware of the fact that we need to bring to this debate other cultural perspectives or, as Boaventura Santos would say, "the epistemologies of the South" ${ }^{16}$ It was our intention to state some preliminary ideas about this complex horizon that is now opened before us. We face a challenging scenario, where big corporations try to impose a classicist, commercialized, consumerist non critical network, as well as information and knowledge flows, behavioral and educational patterns that are congruent with accelerated capital accumulation and cultural control.

If we want to defend life, participate in the construction of a new civilization, enhance our cultural diversity and become emancipated to build healthy societies,, we must incorporate in our research, teaching and preventive agendas a creative and informed action program to expand the democratic and safe network domains of an open access network.

\section{REFERENCES}

1. Pew Research Center. The Internet of Things Will Thrive by 2025. [cited May 14 2014]. Available at: http:// www.pewinternet.org/2014/05/14/internet-of-things

2. Jorge Veraza. Subsunción real del consumo al capital. México: Editorial Itaca; 2008.

3. Andrés Barreda. Economía ecológica y ecología crítica. Seminario del Doctorado en salud colectiva ambiente y sociedad. Quito: Universidad Andina Simón Bolívar del Ecuador; 2010.
4. Diccionario de Informática. Definición de Ciberespacio¿Qué Es Ciberespacio?. 2013. [cited July 2]. Available at: http:/ / www.alegsa.com.ar/Dic/ ciberespacio.php

5. Petras J. El Significado Esencial Del Espionaje Masivo de EEUU. 2013. [cited July 2]. Available at: http:// www.contrainjerencia.com/?p=70110

6. Fumagalli A. Bioeconomía y Capitalismo Cognitivo: Hacia Un Nuevo Paradigma de Acumulación. Madrid: Traficantes de sueños; 2010. p. 87-8. 
7. Ziman J. Real Science: What It Is, and What It Means. Cambridge; New York, NY: Cambridge University Press; 2002.

8. Ford A. La marca de la bestia. Colombia: Editorial Norma; 2001. p. 173-220.

9. Arthur C. How Low-paid Workers at 'Click Farms' Create Appearance of Online Popularity, Technology. The Guardian. 2013. [cited 2015 Aug 29]. Available at: http: / www.theguardian.com/technology/2013/ aug/02/ click-farms-appearance-online-popularity

10. Nájar A. ¿Cuánto poder tienen los Peñabots, los tuiteros que combaten la crítica en México? News. BBC Mundo. 2015 March 17. [cited 2015 Aug 29]. Available at: http:/ / www.bbc.com/mundo/noticias/2015/03/150317_ mexico_internet_poder_penabot_an.

11. Carroll R. Oakland: the city that told Google to get lost. The Guardian. February 11, 2014. [cited 2015 Aug 29]. Available at: http: / /www.theguardian.com/technology/2014/ feb/10/ city-google-go-away-oakland-california

12. Lye. On Oakland's Creepy New Surveillance Program. Common Dreams. 2013. [cited August 2]. Available at: http:/ /www.commondreams.org/view/2013/08/02-7

13. Foray D. L.'economie de la connaissance. Paris: La Decouverte; 2000.

14. Cámara de Diputados del Brasil. 2014. Proyecto de ley de marco civil de internet (PL 2126/11), aprobado en marzo 25.

15. Greenfield S, Babbs D. Is the Internet Bringing Out the Best in Us? Five-minute Video Debate. The Guardian. 2013. [cited July 17]. Available at: http://www. guardian.co.uk/commentisfree/video/2013/jul/15/ internet-susan-greenfield-david-babbs-video-debate

16. Santos BS. Epistemologies of the South: Justice against Epistemicide. 1st ed. Boulder: Paradigm Publishers; 2014. 